\title{
BMJ Open Emergency department visits and hospitalisations for emergent asthmatic symptoms from 2014 to 2016: cross- sectional study in Korea
}

Kyungseon Choi, Sola Han, Hae Sun Suh

To cite: Choi K, Han S, Suh HS. Emergency department visits and hospitalisations for emergent asthmatic symptoms from 2014 to 2016: cross-sectional study in Korea. BMJ Open 2020;10:e036237. doi:10.1136/ bmjopen-2019-036237

- Prepublication history for this paper is available online. To view these files, please visit the journal online (http://dx.doi. org/10.1136/bmjopen-2019036237).

$\mathrm{KC}$ and SH contributed equally.

$\mathrm{KC}$ and SH are joint first authors.

Received 06 December 2019 Revised 06 April 2020 Accepted 30 June 2020

\section{ABSTRACT}

Objective To evaluate the characteristics of emergent patients with asthma who visited emergency departments (EDs) in Korea, and the consequences of these visits. Design Retrospective cross-sectional study. Setting We used data from the National Emergency Department Information System database from 2014 to 2016. The data included reports collected from 408 EDs in Korea.

Participants We analysed the ED cases for asthmarelated emergent symptoms that met the following inclusion criteria: (1) had a main diagnosis code of asthma (International Classification of Diseases 10th Revision code: J45/J46), and (2) recorded as an emergent symptom in the EDs.

Results During 2014-2016, there were 58713 ED visits related to an asthma diagnosis with emergent symptoms. Following an ED visit, $31.69 \%$ were hospitalised, of which $89.88 \%$ were admitted to the general wards, and $10.12 \%$ to the intensive care units (ICUs). More than $50 \%$ of the hospitalised cases included in the group $\geq 70$ years of age. The incidence of death during hospitalisation generally increased with age and the proportion of death in ICU exceeded $10 \%$ among the group $\geq 70$ years. The ratio of ICU/general ward admission at the arrival time of 0-03:00, in the $\geq 60$ years age group was the highest compared with other times of the day and age groups.

Conclusions We found that among all age groups, ED visits by older patients resulted in more ICU admissions. Our results can help in providing a better understanding of medical resource utilisation by emergent patients with asthma.

\section{INTRODUCTION}

Asthma is a chronic disease accompanied by narrowing of the airways. ${ }^{1}$ Globally, there are 300 million patients with asthma. ${ }^{2}$ About 13.8 million disability-adjusted life years are lost annually due to asthma and this is $1.8 \%$ of the total global disease burden. ${ }^{3}$ The disease burden of asthma is known to vary with the presence or the severity of exacerbation. ${ }^{45}$ Exacerbation, especially severe exacerbation, can cause higher medical cost in patients with asthma. $^{5}$
Strengths and limitations of this study

- Emergency department visits and hospitalisation due to asthma exacerbation have been considered as important risk factors of asthma-related death, in addition to negatively impacting the medical costs.

- This study is the first to report data on the use of healthcare resources and deaths following exacerbations based on guideline-recommended clinical pathways by using a nationwide emergency department database.

- It was not possible to determine the severity of emergent symptom, because detailed information like the medications used in emergency departments was not available.

Severe exacerbations in patients with asthma can be life threatening and can exert a significant burden on not only patients but also on the society because of their negative impact on health-related quality-of-life and medical costs. ${ }^{6-8}$ Based on the American Thoracic Society/European Respiratory Society recommendation, the definition of severe exacerbations should include at least one of the following: (1) exacerbations requiring (additional) use of systemic corticosteroids; (2) exacerbations requiring hospitalisation or emergency department (ED) visit and systemic corticosteroids due to asthma. ${ }^{9}$ ED visits and hospitalisation, especially to the intensive care unit (ICU) for asthma have been considered as important risk factors for asthma-related death, in addition to having a huge impact on the medical cost. ${ }^{6}$ Thus, investigating ED visits and hospitalisations for asthma is important to understand the disease burden of patients with asthma.

In the Global Initiative for Asthma (GINA) recommendation, if patients are presenting signs of severe exacerbation, immediate access or transfer to acute care facility (eg, ED) is strongly recommended. The decision 
to hospitalise or discharge is made after managing them in the acute care facility. ${ }^{6}$ Most studies have examined the utilisation of healthcare resources following an exacerbation in a cross-sectional way. ${ }^{810}$ They mostly present the proportion of patients who were hospitalised or visited EDs and outpatient clinics, but not the sequential proportion of healthcare resources used, such as the proportion of hospitalised cases following ED visits. It is, therefore, important to understand the healthcare utilisation and the consequences caused by exacerbation based on the clinical pathways in line with the GINA exacerbation management process.

We aimed to evaluate the demographics and clinical characteristics of emergent patients with asthma who visited EDs in Korea from 2014 to 2016 and assess the consequences of these visits.

\section{METHODS}

\section{Data source}

We conducted a nationwide, cross-sectional study by using the National Emergency Department Information System (NEDIS) data from 2014 to 2016. This included reports from 375, 403 and 408 EDs in 2014, 2015 and 2016, respectively. These data included demographic and clinical characteristics of the patients, time of their visits, means of arrival, ED discharge diagnosis codes based on the International Classification of Diseases 10th Revision (ICD-10) and consequences of the ED visits.

\section{Study population}

We included ED visit cases which met all of the following criteria for the analysis: (1) cases with a main diagnosis code of asthma (ICD-10 code: J45 or J46); (2) cases recorded as an emergent symptom in EDs. We used the variable 'emergent symptom: yes/no' to find $\mathrm{ED}$ visit cases with an emergent symptom from the database. We defined asthma based on the diagnosis codes which were physician diagnosed, not self-reported. In addition, because the diagnosis codes were listed in order of importance, we identified cases with a main diagnosis code (ie, first-listed diagnosis code) of asthma.

\section{Outcome measures}

We evaluated the demographics and clinical characteristics of emergent patients with asthma who visited EDs in Korea and analysed the consequences of these visits. The evaluated characteristics included age, sex, types of insurance, means of arrival, chief complaints and comorbidities. We defined comorbidities (ie, disease categories of Charlson Comorbidity Index ${ }^{11}$ and chronic obstructive pulmonary disease (COPD)) based on the diagnosis codes. The consequences of the visit included discharge, transfer to another ED, death in ED, hospitalisation (general ward or ICU), death during hospitalisation and others (ie, missing or unknown). We further evaluated the hospitalised cases following an ED visit based on age groups, years, seasons or time of ED visits. Only the first change in disposition following an ED visit was included in the analysis of consequences.

\section{Statistical analyses}

The unit of analysis in this study was an ED visit, and not a patient because the patients' unique identifiers were not included in the data. While categorical variables were presented as numbers with percentages, continuous variables were presented as mean with standard deviations. The annual trends from 2014 to 2016 were tested using the linear-by-linear association test for categorical variables and analysis of variance for continuous variables and were presented as a $\mathrm{p}$ value for trend. A two-tailed $\mathrm{p}<0.05$ was considered statistically significant. All analyses were performed using IBM SPSS version 22.0 (SPSS Inc., Chicago, IL, USA) and SAS version 9.4 (SAS Inc., Cary, NC, USA).

\section{Patient and public involvement}

This research was done without patient involvement. Patients were not invited to comment on the study design and were not consulted to develop patient relevant outcomes or interpret the results. Patients were not invited to contribute to the writing or editing of this document for readability or accuracy.

\section{RESULTS}

\section{Demographic and clinical characteristics}

During 2014 to 2016, 25545841 ED visits were recorded in the NEDIS, of which 77883 visits had a main diagnosis of asthma (ICD-10 code: J45 or J46). Among these 77883 ED visits, $75.40 \%(n=58713)$ were identified as emergent cases and were used for the analysis as emergent asthmatic cases. The mean age was $44.19 \pm 27.17$ years. The age groups of $0-11$ and $12-17$ years showed decreasing trends of ED visits during 2014 to $2016(\mathrm{p}<0.05)$. In contrast, during the same period, the adult groups (age groups of 18-29, 40-49, 60-69 and $\geq 80$ years) showed increasing trends of ED visits ( $\mathrm{p}<0.001$ for all groups). While female accounted for $49.47 \%$ of the entire study population, they were $53.98 \%$ of the adult population (aged $\geq 18$ years). The top five chief complaints of emergent patients with asthma were dyspnoea $(53.69 \%)$, cough $(11.62 \%)$, fever $(3.36 \%)$, sputum $(1.42 \%)$ and chest discomfort $(1.09 \%)$. Among baseline comorbidities, COPD was $2.20 \%$ (table 1).

\section{Consequences: overall}

Following an ED visit, while $66.04 \%$ of the patients were discharged from the EDs, 31.69\% were hospitalised, $0.10 \%$ died in EDs, $1.89 \%$ were transferred to other EDs and $0.29 \%$ were unknown or missing. Among the hospitalised cases after an ED visit, $89.88 \%$ were admitted to general wards, and $10.12 \%$ to ICUs.

\section{Consequences: hospitalised cases after an ED visit}

The proportion of hospitalised cases based on age groups followed a U-shaped trend. In the age groups $\geq 70$ years, 
Table 1 Demographic and clinical characteristics of emergency department visit cases with asthma-related emergent symptom from 2014 to 2016 in Korea

\begin{tabular}{|c|c|c|c|c|c|}
\hline \multirow[b]{3}{*}{ Variables } & \multirow[b]{2}{*}{$\begin{array}{l}\begin{array}{l}\text { Overall } \\
(\mathrm{N}=58713)\end{array} \\
\end{array}$} & \multicolumn{3}{|c|}{ Years } & \multirow[b]{3}{*}{ P value } \\
\hline & & $\begin{array}{l}2014 \\
(\mathrm{~N}=18042)\end{array}$ & $\begin{array}{l}2015 \\
(\mathrm{~N}=19602)\end{array}$ & $\begin{array}{l}2016 \\
(\mathrm{~N}=21069)\end{array}$ & \\
\hline & N (\%) & N (\%) & N (\%) & N (\%) & \\
\hline Age, mean in years (SD) & $44.19(27.17)$ & $42.04(27.57)$ & $44.94(27.11)$ & $45.34(26.76)$ & $<0.001$ \\
\hline \multicolumn{6}{|l|}{ Age group } \\
\hline $0-11$ & $11299(19.24)$ & $4130(22.89)$ & $3587(18.30)$ & $3582(17.00)$ & $<0.001$ \\
\hline $18-29$ & $5672(9.66)$ & $1611(8.93)$ & $1868(9.53)$ & $2193(10.41)$ & $<0.001$ \\
\hline 30-39 & 5240 (8.92) & $1578(8.75)$ & 1763 (8.99) & $1899(9.01)$ & 0.366 \\
\hline $40-49$ & $6530(11.12)$ & $1878(10.41)$ & 2165 (11.04) & $2487(11.8)$ & $<0.001$ \\
\hline $50-59$ & 7415 (12.63) & $2240(12.42)$ & $2484(12.67)$ & $2671(12.77)$ & 0.295 \\
\hline $0-11$ & $3770(33.37)$ & $1433(34.70)$ & $1167(32.53)$ & $1170(32.66)$ & 0.052 \\
\hline $12-17$ & $1170(42.31)$ & $380(42.08)$ & 415 (44.39) & $375(40.45)$ & 0.473 \\
\hline $18-29$ & $2998(52.86)$ & 839 (52.08) & $1035(55.41)$ & $1124(51.25)$ & 0.459 \\
\hline $30-39$ & $2953(56.35)$ & $933(59.13)$ & $983(55.76)$ & $1037(54.61)$ & 0.008 \\
\hline $40-49$ & $3248(49.74)$ & $982(52.29)$ & 1069 (49.38) & $1197(48.13)$ & 0.007 \\
\hline $50-59$ & $3523(47.51)$ & $1054(47.05)$ & $1198(48.23)$ & $1271(47.23)$ & 0.938 \\
\hline $60-69$ & $2775(48.03)$ & $812(48.36)$ & $898(46.87)$ & 1065 (48.79) & 0.723 \\
\hline $70-79$ & $4410(56.17)$ & $1336(55.74)$ & $1572(58.22)$ & $1502(54.54)$ & 0.331 \\
\hline $80+$ & 4196 (68.08) & 1089 (66.97) & 1492 (68.32) & 1615 (68.64) & 0.286 \\
\hline Ambulance & 11590 (19.74) & $3473(19.25)$ & $3946(20.13)$ & $4171(19.80)$ & 0.201 \\
\hline Walk & 43799 (74.6) & 12577 (69.71) & $14747(75.23)$ & 16475 (78.20) & $<0.001$ \\
\hline Car & 2952 (5.03) & $1798(9.97)$ & $804(4.10)$ & $350(1.66)$ & $<0.001$ \\
\hline Otherł & $372(0.63)$ & $194(1.08)$ & $105(0.54)$ & $73(0.35)$ & $<0.001$ \\
\hline \multicolumn{6}{|l|}{ Chief complaints§ } \\
\hline Dyspnoea & 31516 (53.69) & $10140(56.20)$ & $10085(51.45)$ & 11291 (53.59) & $<0.001$ \\
\hline Cough & $6821(11.62)$ & 2251 (12.48) & $2241(11.43)$ & $2329(11.05)$ & $<0.001$ \\
\hline Fever & $1972(3.36)$ & 701 (3.89) & $540(2.75)$ & $731(3.47)$ & 0.044 \\
\hline Sputum & 835 (1.42) & 232 (1.29) & $292(1.49)$ & $311(1.48)$ & 0.124 \\
\hline Chest discomfort & 639 (1.09) & $177(0.98)$ & $226(1.15)$ & $236(1.12)$ & 0.203 \\
\hline Wheezing & $492(0.84)$ & $164(0.91)$ & $171(0.87)$ & $157(0.75)$ & 0.072 \\
\hline Dyspnoea acute & $446(0.76)$ & $158(0.88)$ & $123(0.63)$ & $165(0.78)$ & 0.351 \\
\hline Chest pain & $415(0.71)$ & $134(0.74)$ & $144(0.73)$ & $137(0.65)$ & 0.266 \\
\hline Asthma & $365(0.62)$ & $145(0.80)$ & $123(0.63)$ & $97(0.46)$ & $<0.001$ \\
\hline Abdominal pain & $268(0.46)$ & $115(0.64)$ & $78(0.40)$ & $75(0.36)$ & $<0.001$ \\
\hline \multicolumn{6}{|l|}{ Comorbidities } \\
\hline Myocardial infarction & $82(0.14)$ & $16(0.09)$ & $24(0.12)$ & $42(0.20)$ & 0.003 \\
\hline Congestive heart failure & $575(0.99)$ & $132(0.73)$ & $183(0.93)$ & $260(1.23)$ & $<0.001$ \\
\hline
\end{tabular}


Table 1 Continued

\begin{tabular}{|c|c|c|c|c|c|}
\hline \multirow[b]{3}{*}{ Variables } & \multirow[b]{2}{*}{$\begin{array}{l}\text { Overall } \\
(\mathrm{N}=58713)\end{array}$} & \multicolumn{3}{|c|}{ Years } & \multirow[b]{3}{*}{ P value* } \\
\hline & & $\begin{array}{l}2014 \\
(\mathrm{~N}=18042)\end{array}$ & $\begin{array}{l}2015 \\
(\mathrm{~N}=19602)\end{array}$ & $\begin{array}{l}2016 \\
(\mathrm{~N}=21069)\end{array}$ & \\
\hline & $\mathbf{N}(\%)$ & $\mathbf{N}(\%)$ & N (\%) & N (\%) & \\
\hline Peripheral vascular disease & $21(0.04)$ & $9(0.05)$ & $3(0.02)$ & $9(0.04)$ & 0.772 \\
\hline Cerebrovascular disease & $93(0.16)$ & $29(0.16)$ & $30(0.15)$ & $34(0.16)$ & 0.979 \\
\hline Rheumatic disease & $22(0.04)$ & $9(0.05)$ & $6(0.03)$ & $7(0.03)$ & 0.412 \\
\hline Peptic ulcer disease & $77(0.13)$ & $50(0.28)$ & $17(0.09)$ & $10(0.05)$ & $<0.001$ \\
\hline Mild liver disease & $97(0.17)$ & $24(0.13)$ & $43(0.22)$ & $30(0.14)$ & 0.901 \\
\hline Diabetes without chronic complication & $407(0.70)$ & $117(0.65)$ & $166(0.85)$ & $124(0.59)$ & 0.393 \\
\hline Any malignancy†† & $165(0.28)$ & $47(0.26)$ & $64(0.33)$ & $54(0.26)$ & 0.885 \\
\hline Moderate or severe liver disease & $4(0.01)$ & $0(0.00)$ & $1(0.01)$ & $3(0.01)$ & 0.086 \\
\hline Metastatic solid tumour & $8(0.01)$ & $0(0.00)$ & $3(0.02)$ & $5(0.02)$ & 0.046 \\
\hline AIDS/HIV & $0(0.00)$ & $0(0.00)$ & $0(0.00)$ & $0(0.00)$ & NC \\
\hline Chronic obstructive pulmonary disease & $1278(2.20)$ & $370(2.05)$ & $424(2.16)$ & $484(2.30)$ & 0.095 \\
\hline
\end{tabular}

${ }^{*} P$ values were calculated for data from 2014 to 2016 with the linear-by-linear association test for categorical variables and analysis of variance for continuous variables. P values for some variables (chronic pulmonary disease and AIDS/HIV) could not be calculated because data from 2014 to 2016 were either 0 or $100 \%$.

†Auto insurance, workers' compensation insurance and private insurance.

$\ddagger$ Aeroplane, bicycle and motorcycle.

$\S$ The top 10 most common chief complaints were listed. Multiple responses were allowed for this variable.

१The comorbidities used all ED discharge diagnosis codes of the patient.

${ }^{* *}$ Chronic pulmonary disease can only be $100 \%$ because this disease category from Charlson Comorbidity Index included asthma diagnosis codes (J45/J46).

††Malignancy include lymphoma and leukaemia, except malignant neoplasm of skin.

NC, not calculated.

more than half of the ED visit cases were hospitalised (figure 1A). The number and proportion of deaths in the general wards and ICUs generally increased with age (figure 1B).
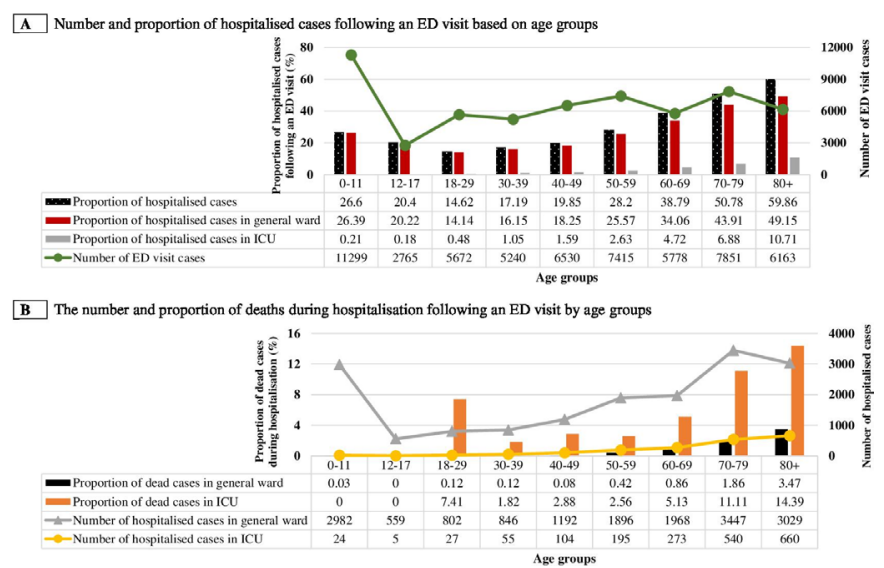

Figure 1 Number and proportion of (A) hospitalised cases and (B) deaths during hospitalisation following an emergency department (ED) visit according to age groups. ICU, intensive care unit.
While the hospitalisation (total and general wards) case in the age group $\leq 11$ years peaked in autumn, those in age group $\geq 50$ years was predominantly in spring and winter (figure $2 \mathrm{~A}$ and $\mathrm{B}$ ). Additionally, the hospitalisation of individuals $\geq 70$ years to ICUs also peaked in spring
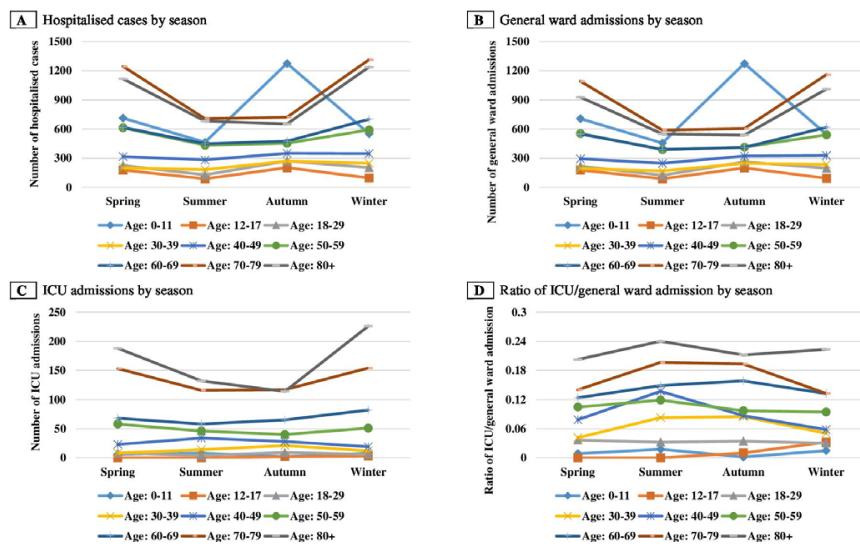

Figure 2 Number and ratio of hospitalised cases following an emergency department visit by (A-D) season. ICU, intensive care unit. 

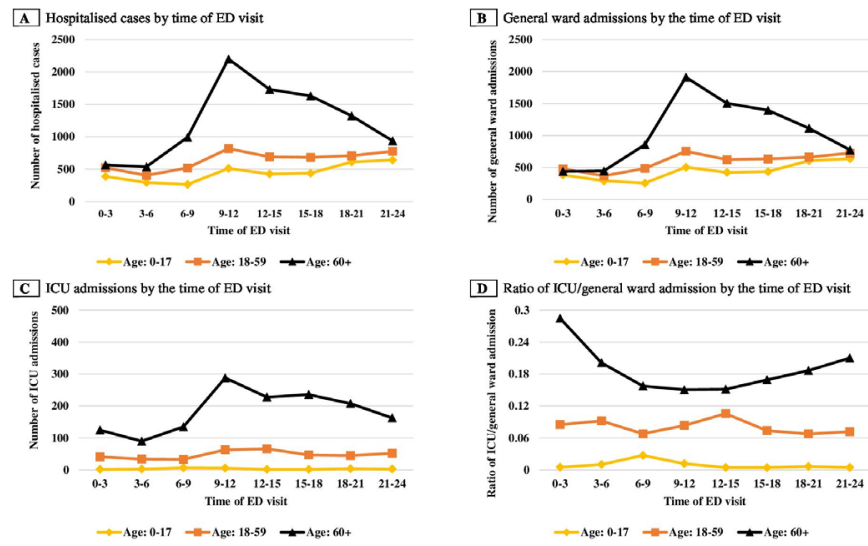

Figure 3 Number and ratio of hospitalised cases following an emergency department (ED) visit by (A-D) time of ED visit. ICU, intensive care unit.

and winter (figure 2C). The ratio of ICU/general ward admission showed parallel seasonal trends in general (figure 2D).

Based on the time of ED visits, the number of hospitalised cases (total, general wards and ICUs) varied between the different age groups. It peaked between 9:00 and 12:00 for the $\geq 60$ years group (figure $3 \mathrm{~A}-\mathrm{C}$ ). The ratio of ICU/general ward admission at the arrival time of 0-3:00 in the $\geq 60$ years group was the highest compared with all other times of visit and age groups (figure 3D).

\section{DISCUSSION}

Of 58713 ED visits, $31.69 \%$ were hospitalised and $0.10 \%$ died. The older they were, the more hospitalisation and death, and more patients died in general wards or ICUs. Depending on the season and time of ED visit, the number of hospitalisations, general wards and ICUs admission cases and ratio of ICU/GE admission differed by the patient's age.

As per the GINA recommendations, patients with severe asthmatic exacerbation should be managed first in an acute care facility such as an ED. ${ }^{6}$ To the best of our knowledge, this is the first study that provides comprehensive information on the use of medical resources, as well as the incidence of deaths following asthmatic exacerbations based on the clinical pathway by using a nationwide ED database. In order to clarify the interpretation of the findings, we excluded patients who visited the ED with non-emergent symptoms from the analysis.

This study showed asthma exacerbation requiring ED visits occurred more in boys than girls aged under 18 years. In adults above 18 years, numbers of women with asthma who visited the ED were higher than the numbers of men. Different findings by age and sex were consistent with previous studies. ${ }^{12-14}$

Marked differences were noted in the hospitalised cases following an ED visit among older patients, especially those aged above 70 years compared with the patients who aged under 70 years. The proportion of hospitalised cases and the ratio of ICU/general ward admissions were much higher in older patients. In addition, nocturnal asthma symptoms were also more common in this group. Previous study reported that older patients who visited the ED for asthma had higher rates of healthcare utilisations. ${ }^{15}$ Similarly, this real-world data showed the proportion of adult patients who were hospitalised after ED visit was higher in older patients. This could be because older patients are more likely to (1) be associated with modifiable risk factors for asthma exacerbation (eg, poor adherence, incorrect inhaler technique, smoking or comorbidities), and (2) have worsened lung or other physical functions (eg, immunity) and reduced response to antiasthmatics due to ageing or longer disease duration. ${ }^{6}$ 16-18 An increased exacerbation of asthma in older patients has been reported in previous studies, but this study has an additional significance as it reports on other aspects of increased exacerbation that were not previously reported, such as nocturnal symptoms. ${ }^{13} 16$

\section{Limitations}

This study has several limitations. First, because detailed information regarding the medications used in EDs was not available, we could not determine if systemic corticosteroids were used for the emergent symptoms. However, by excluding patients with non-emergent asthma symptoms, we tried to minimise the impact of relatively mild exacerbations. Second, we were not able to define patients with asthma based on the detailed diagnostic criteria evaluated before ED visit (eg, previous spirometry evaluation records) and were not able to know asthma treatments prescribed for patients before ED visit. These kinds of information were not available in these NEDIS data. However, we tried to define patients with asthma by using the diagnosis codes which were listed as the main diagnosis when the patients visited EDs. Third, we were not able to evaluate patients' smoking history as baseline characteristics, because NEDIS data do not provide this information. Fourth, a unit of analysis in this study was an ED visit and not a patient, since the patients' unique identifiers were not available in the data. Thus, multiple ED visits by the same person could have been included in the analysis. Fifth, our study results may not be generalisable to other countries, with regard to the healthcare system and accessibility. Nevertheless, the use of large-scale ED visit data collected nationwide, from $408 \mathrm{EDs}$, is the major strength of this study.

\section{CONCLUSIONS}

We studied the characteristics of patients who visited EDs for asthma-related emergent symptoms, and the consequences of these visits, by using a nationwide ED database. We found that the ED visits by older patients resulted in more ICU admissions and poorer outcomes than that by other age groups. These results can contribute to a better understanding of medical resource utilisation in emergent patients with asthma. Because severe exacerbations are the most burdensome and potentially life-threatening 
events in patients with asthma, our findings are valuable in planning resource allocation to achieve optimal care for patients with asthma at the population level. ${ }^{6-8}$

Acknowledgements This study result was analysed using the National Emergency Department Information System data N20180120712.

Contributors $\mathrm{KC}$ : data curation, formal analysis, investigation, writing the original draft, review and editing. SH: conceptualisation, data curation, methodology, formal analysis, investigation, writing the original draft, review and editing. HSS: conceptualisation, data curation, methodology, interpretation of data, investigation, supervision, writing the original draft, review and editing.

Funding This work was supported by Pusan National University.

Competing interests None declared.

Patient consent for publication Not required.

Ethics approval The Pusan National University Institutional Review Board exempted the study from ethical review (PNU IRB/2018_55_HR).

Provenance and peer review Not commissioned; externally peer reviewed.

Data availability statement Data may be obtained from a third party (with appropriate authorization approval) and are not publicly available.

Open access This is an open access article distributed in accordance with the Creative Commons Attribution Non Commercial (CC BY-NC 4.0) license, which permits others to distribute, remix, adapt, build upon this work non-commercially, and license their derivative works on different terms, provided the original work is properly cited, appropriate credit is given, any changes made indicated, and the use is non-commercial. See: http://creativecommons.org/licenses/by-nc/4.0/.

ORCID iD

Hae Sun Suh http://orcid.org/0000-0003-3445-6607

\section{REFERENCES}

1 GINA. Online appendix. Global strategy for asthma management and prevention; 2018. https://ginasthma.org [Accessed 26 Mar 2020].

2 Masoli M, Fabian D, Holt S, et al. The global burden of asthma: executive summary of the GINA dissemination Committee report. Allergy 2004;59:469-78.

3 Vos T, Flaxman AD, Naghavi M, et al. Years lived with disability (YLDs) for 1160 sequelae of 289 diseases and injuries 1990-2010: a systematic analysis for the global burden of disease study 2010 . Lancet 2012;380:2163-96.

4 Schwenkglenks M, Lowy A, Anderhub $\mathrm{H}$, et al. Costs of asthma in a cohort of Swiss adults: associations with exacerbation status and severity. Value Health 2003;6:75-83.

5 Borderías Clau L, Zabaleta Murguionda M, Riesco Miranda JA, et al. Coste Y manejo de Una crisis asmática en El ámbito hospitalario de nuestro medio (Estudio COAX en servicios hospitalarios). Archivos de Bronconeumología 2005;41:313-21.

6 GINA. Global strategy for asthma management and prevention, 2018. Available: https://ginasthma.org [Accessed 21 Feb 2019].

7 Peters SP, Ferguson G, Deniz Y, et al. Uncontrolled asthma: a review of the prevalence, disease burden and options for treatment. Respir Med 2006;100:1139-51.

8 Lee YJ, Kwon S-H, Hong S-H, et al. Health care utilization and direct costs in mild, moderate, and severe adult asthma: a descriptive study using the 2014 South Korean health insurance database. Clin Ther 2017;39:527-36.

9 Reddel HK, Taylor DR, Bateman ED, et al. An official American thoracic Society/European respiratory Society statement: asthma control and exacerbations: standardizing endpoints for clinical asthma trials and clinical practice. Am J Respir Crit Care Med 2009:180:59-99.

10 Williams AE, Lloyd AC, Watson L, et al. Cost of scheduled and unscheduled asthma management in seven European Union countries. European Respiratory Review 2006;15:4-9.

11 Quan H, Sundararajan V, Halfon P, et al. Coding algorithms for defining comorbidities in ICD-9-CM and ICD-10 administrative data. Med Care 2005;43:1130-9.

12 Sears MR. Epidemiology of asthma exacerbations. J Allergy Clin Immunol 2008:122:662-8.

13 Lee M-H, Seo H-J, Shin EJ, et al. The age-related characteristics of adults with asthma who visited emergency departments in Korea from 2007 to 2012. Allergy Asthma Proc 2018;39:136-42.

14 Schatz M, Camargo CA. The relationship of sex to asthma prevalence, health care utilization, and medications in a large managed care organization. Ann Allergy Asthma Immunol 2003;91:553-8

15 Tsai C-L, Lee W-Y, Hanania NA, et al. Age-related differences in clinical outcomes for acute asthma in the United States, 2006-2008. J Allergy Clin Immunol 2012;129:1252-8.

16 Bloom Cl, Nissen F, Douglas IJ, et al. Exacerbation risk and characterisation of the UK's asthma population from infants to old age. Thorax 2018;73:313-20.

17 Ulrik CS, Lange P. Decline of lung function in adults with bronchial asthma. Am J Respir Crit Care Med 1994;150:629-34.

18 Rönmark E, Lindberg A, Watson L, et al. Outcome and severity of adult onset asthma--report from the obstructive lung disease in northern Sweden studies (OLIN). Respir Med 2007;101:2370-7. 